\title{
Peroral endoscopic myotomy with endoscopic fundoplication in a patient with idiopathic achalasia
}

A 28-year-old man diagnosed with type II achalasia cardia underwent peroral endoscopic myotomy (POEM) via the anterior route (12-2 o'clock) using the standard technique. In this case we performed an endoscopic fundoplication in addition to the POEM procedure to prevent post-procedure reflux. Inoue et al. recently described the technique of POEM plus fundoplication [1].

The steps of fundoplication were as follows ( Video 1 ). First, the loose areolar tissue was dissected using a coagulation forceps (Coagrasper G, FD-412LR; Olympus, Tokyo, Japan). Subsequently, a small opening was created in the peritoneum and enlarged using the coagulation forceps ( $\triangleright$ Fig. 1). The scope was inserted into the peritoneum, and the serosal aspect of the stomach and surface of the liver were visualized (\$ Fig.2). An ultraslim endoscope was passed into the gastric lumen to help in selecting an appropriate site along the anterior gastric wall. The selected site was marked with a coagulation forceps for later identification ( Fig.3). Subsequently, the scope was pulled out and re-introduced into the peritoneal cavity with an endoloop-endoclip unit. Multiple endoclips were applied along the anterior gastric wall ( $\triangleright$ Fig.4). The scope was withdrawn from the peritoneal cavity to the distal end of the myotomy, where a second series of endoclips was applied ( $>$ Fig. 5). The endoloop was then tightened and the redundant part of the endoloop trimmed using an endoscopic loop cutter. On endoscopy, with the scope in the retroflexed position, the fundoplication wrap could be seen ( Fig.6).

POEM is a safe and effective treatment option for achalasia cardia [2]. However, the incidence of gastroesophageal reflux is high after POEM [3]. Recently, Inoue et al. described a novel technique of natural
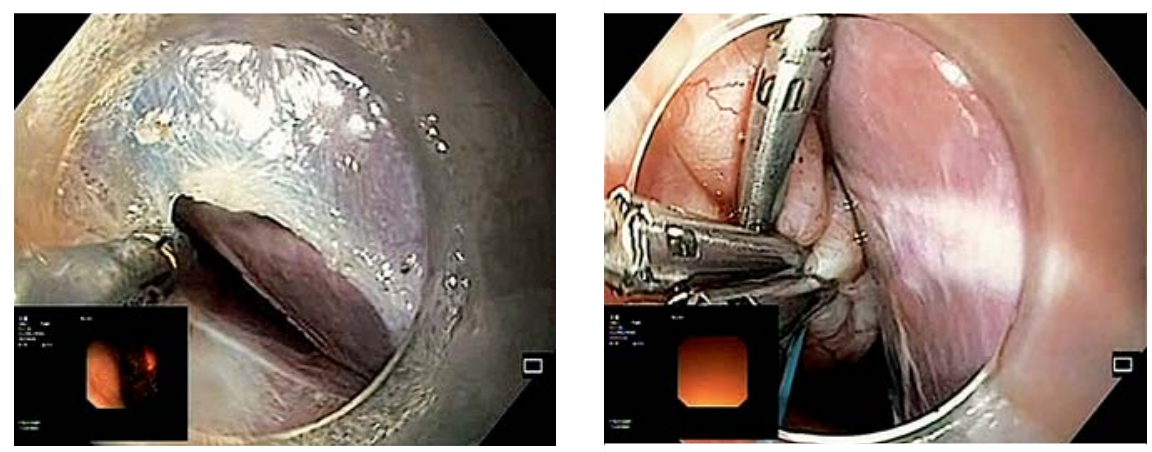

- Fig. 1 Endoscopic fundoplication following peroral endoscopic myotomy (POEM) for achalasia: creation of a small opening in the peritoneum.

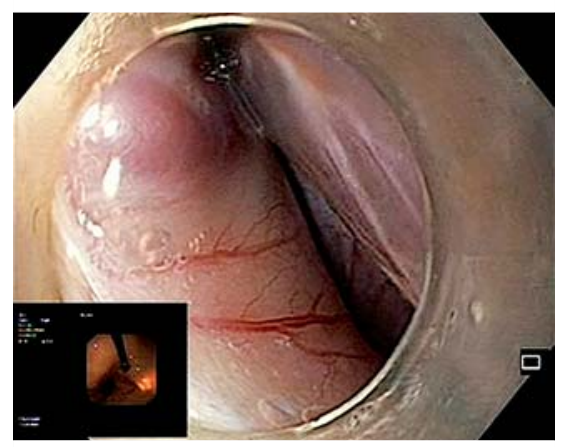

- Fig. 2 Entry into the peritoneal cavity and identification of gastric wall (on left) and surface of liver (on right).

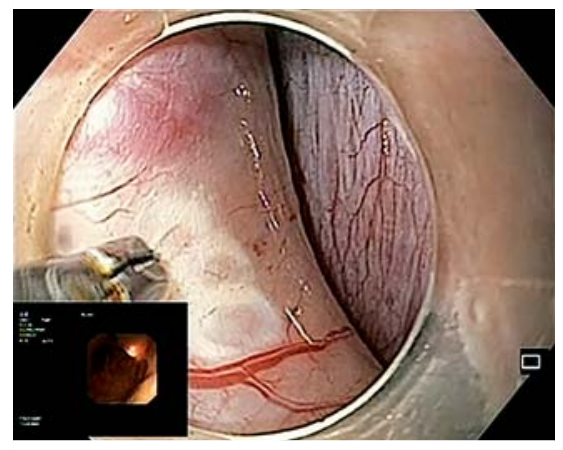

Fig. 3 Marking of an appropriate site along the anterior gastric wall using coagulation forceps.

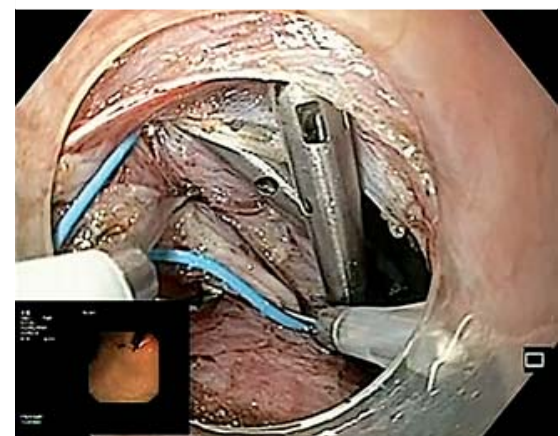

Fig. 5 Application of second series of endoclips along the distal edge of the myotomy site.

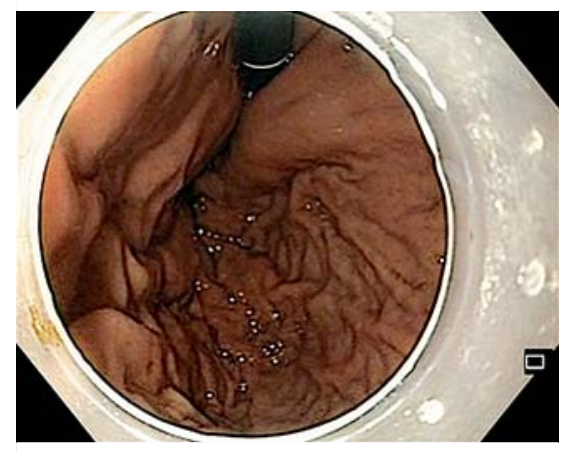

Fig. 6 Endoscopic visualization of the partial fundoplication wrap. 


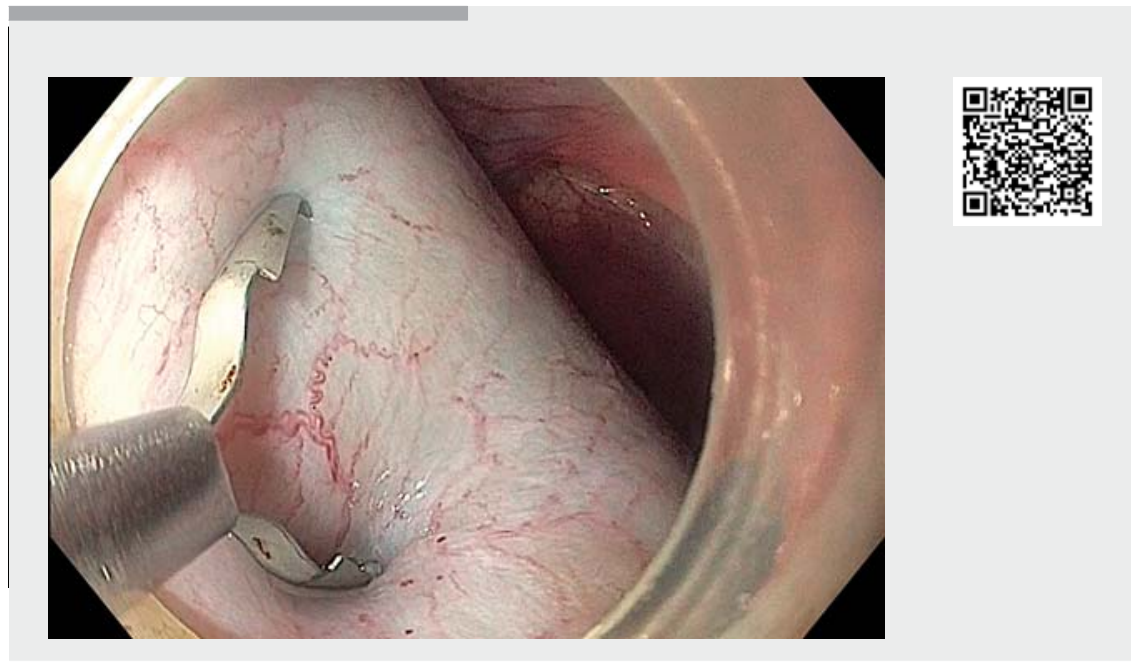

$\checkmark$ Video 1 Peroral endoscopic myotomy (POEM) with fundoplication using the principles of natural orifice transluminal endoscopic surgery (NOTES).

orifice transluminal endoscopic surgery (NOTES) fundoplication in patients who underwent POEM [1]. This is a novel and minimally invasive technique to prevent gastroesophageal reflux after POEM. However, the efficacy and long-term durability of endoscopic fundoplication remain to be seen [4].

Endoscopy_UCTN_Code_TTT_1AO_2AJ

\section{Competing interests}

None

Zaheer Nabi, Mohan Ramchandani, Santosh Darisetty, Rama Kotla, D. Nageshwar Reddy India

\section{Corresponding author}

\section{Zaheer Nabi, MD} Somajiguda, Hyderabad - 500 082, India Fax: +91-40-2332 4255

zaheernabi1978@gmail.com
[1] Inoue H, Ueno A, Shimamura Y et al. Peroral endoscopic myotomy and fundoplication: a novel NOTES procedure. Endoscopy 2019; 51: $161-164$

[2] Nabi Z, Ramchandani M, Chavan R et al. Peroral endoscopic myotomy for achalasia cardia: outcomes in over 400 consecutive patients. Endosc Int Open 2017; 5: E331 - E339

[3] Repici A, Fuccio L, Maselli R et al. GERD after per-oral endoscopic myotomy as compared with Heller's myotomy with fundoplication: a systematic review with meta-analysis. Gastrointest Endosc 2018; 87: 934 - 943 e918

[4] Reddy DN. Peroral endoscopic myotomy with fundoplication: are we there yet! Endoscopy 2019; 51: 111-112

\section{Bibliography}

DOI https://doi.org/10.1055/a-0978-4627

Published online: 9.8.2019

Endoscopy 2020; 52: 74-75

(c) Georg Thieme Verlag KG

Stuttgart - New York

ISSN 0013-726X

Asian Institute of Gastroenterology, Hyderabad,

Asian Institute of Gastroenterology, 6-3-661,

\section{ENDOSCOPY E-VIDEOS}

https://eref.thieme.de/e-videos

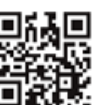

Endoscopy E-Videos is a free access online section, reporting on interesting cases and new

techniques in gastroenterological endoscopy. All papers include a high quality video and all contributions are freely accessible online.

This section has its own submission website at

https://mc.manuscriptcentral.com/e-videos 